\title{
Redes sociales, empatía y solidaridad ciudadana en jóvenes universitarios. Ciudad de México 2017
}

\section{Social networks, empathy and citizen solidarity in university youth. Ciudad de México 2017}

\author{
MARÍA ISABEL ARBESÚ GARCÍA* \\ JUAN MANUEL PIÑA OSORIO**
}

Este documento presenta los resultados de una investigación cuyo objetivo fue indagar las distintas formas de participación emprendidas por los jóvenes después del terremoto de 2017 en la Ciudad de México y comprender las razones que los motivaron. El diseño del estudio fue cualitativo y exploratorio, y la técnica consistió en un cuestionario en línea con preguntas abiertas. El referente empírico se constituyó de 41 jóvenes universitarios. Los datos se examinaron por medio de un análisis temático inductivo. Los resultados indican que los jóvenes emplearon su habilidad en el uso de redes sociales para comunicarse con amigos, compañeros e, incluso, con desconocidos con el objeto de informarse e informar en qué zonas de la ciudad requerían ayuda. La empatía y la solidaridad les brindó la posibilidad de ponerse en el lugar de las personas damnificadas y realizar múltiples acciones para ayudar a quienes se encontraban en desgracia.

This document proposes ascertain the distinct forms of participation undertaken by young people after the earthquake of 2017, and understand the reasons that motivated them to take such actions. A qualitative and exploratory technique was used in an online questionnaire with open ended questions. The empiric representation was made up of 41 university youths. The data was analyzed by means of an inductive topic. The results show that these young people utilized their ability in the use of social networks to communicate with friends, classmates and including with strangers, with the objective to inform themselves and others about the zones of the city that required help. Empathy and solidarity offer them the possibility to put themselves in the place of those victims and carry out multiple actions to aid those in difficulty.
Palabras clave:

jóvenes universitarios, redes sociales, empatía, solidaridad

\section{Keywords:}

university youth, social networks, empathy, solidarity

Recibido: 17 de febrero de 2020 | Aceptado para su publicación: 30 de septiembre de 2020 | Publicado: 11 de noviembre de 2020

Recuperado de: https://sinectica.iteso.mx/index.php/SINECTICA/article/view/1097

doi: 10.31391/S2007-7033(2020)0055-012

\footnotetext{
* Doctora en Educación. Profesora e investigadora en la Universidad Autónoma Metropolitana, Unidad Xochimilco. Miembro del Sistema Nacional de Investigadores. Líneas de investigación: análisis y evaluación de la docencia y la enseñanza en educación superior, representaciones sociales, actores de la educación superior y formación de profesores. Correo electrónico: isabel.arbesu@gmail.com

** Doctor en Pedagogía. Investigador del Instituto de Investigaciones sobre la Universidad y la Educación de la UNAM. Miembro del Sistema Nacional de Investigadores. Líneas de investigación: Cultura ciudadana y cultura política en estudiantes de educación superior. Correo electrónico: jmpo@unam.mx
}

Nuestro agradecimiento a la doctora Gabriela Argumedo García por su ayuda en el manejo del software Nvivo. 


\section{INTRODUCCIÓN}

1 mismo día en que se cumplían treinta dos años del terremoto que ocurrió en la Ciudad de México sucedió lo inimaginable: un terremoto de 7.1 grados (Servicio Sismológico Nacional, 2018) sacudía de nuevo la ciudad, con consecuencias en ocho entidades del país que provocaron daños en más de 140,000 edificaciones. La pérdida total fue de casi 50,000 construcciones, las cuales, en su mayoría, eran de tipo habitacional. De igual modo, de acuerdo con los datos oficiales, se calcula que fallecieron alrededor de 400 personas (Senado de la República, 2017).

Una gran cantidad de jóvenes, muchos de ellos estudiantes, salieron a las calles para ayudar en las labores de rescate de las víctimas atrapadas por los escombros; organizaron centros de acopio, trajeron y llevaron víveres en bicicleta. A simple vista, los jóvenes fueron la fuerza principal y con mayor iniciativa solidaria de la sociedad civil mexicana. Si recurrimos a la información oficial, constatamos que algunas encuestas, realizadas por medios de comunicación, muestran que el perfil de la participación ciudadana era juvenil en su mayoría; por ejemplo, el 74\% de los jóvenes encuestados menores de treinta años afirmaron que ante la emergencia se volcaron a las calles para ayudar a las personas que lo requerían (Moreno, 2017).

Uno de los autores de este artículo, quien trabaja en una institución pública ubicada al sur de esta ciudad, decidió tomarse el tiempo que duraba su clase para hablar con sus estudiantes sobre este lamentable suceso. Los jóvenes que cursaban el último año de la licenciatura en Diseño Industrial se explayaron y platicaron todo lo que habían hecho para poder ayudar a sus vecinos, familiares, conocidos y también a personas desconocidas. Todos estos relatos nos motivaron a llevar a cabo un trabajo de investigación cualitativa, con dos objetivos: indagar las distintas formas de participación emprendidas por los jóvenes después del terremoto del 19 de septiembre de 2017, y comprender las razones que los motivaron para concretar esas acciones.

En el primer apartado analizamos el impacto que han tenido las redes sociales, especialmente en la población joven, al convertirse en una nueva modalidad de socialización. En el segundo, destacamos el papel de la solidaridad y, en particular, la de los estudiantes universitarios actuales. En el siguiente explicamos el método de la investigación y los diversos pasos que seguimos para la elaboración de las categorías temáticas. Posteriormente, exponemos los resultados obtenidos, todo expresado por los universitarios que colaboraron en esta indagación, así como nuestras conclusiones.

\section{LOS JÓVENES Y LOS DISPOSITIVOS TECNOLÓGICOS}

En la sociedad contemporánea se presentan nuevas formas de comunicación vinculadas a internet, sus dispositivos, sus numerosas plataformas y las redes sociales. Estas se utilizan para numerosas actividades, como promover productos novedosos; buscar servicios profesionales; efectuar campañas y debates políticos; realizar transferencias bancarias o pagos; hacer rastreos biblio- y hemerográficos; $y$, en especial, como canal de comunicación constante entre personas, grupos o comunidades (Ruano, Cogote y Torres, 2016; Aguilar y Said, 2010; Lévy, 2007; Castells, 2002).

Para Medina (2007), no se trata solo del cambio en la técnica o artefactos electrónicos, sino que es la llegada de una cultura digital que ha logrado modificar antiguas

Arbesú / Piña. Redes sociales, empatía y solidaridad ciudadana en jóvenes universitarios. Ciudad de México 2017 Sinéctica 55 www.sinectica.iteso. $m x$ 
prácticas por unas innovadoras, enmarcadas en dispositivos tecnológicos, redes y medios de información. La cultura digital integra la red internacional, los instrumentos o dispositivos tecnológicos y la organización social, en este caso, las redes (Lévy, 2007), e involucra la producción científica, la fabril, la agrícola, el comercio, la administración y muchas más.

En la vida diaria de las personas, estos elementos están presentes: internet a la mano, dispositivo fijo o portátil y una o varias redes para entrar en comunicación. Un teléfono portátil permite a su usuario conectarse a la red internacional para entablar comunicación a nivel local, nacional o internacional. Cada persona recibe de manera cotidiana información de diverso tipo, la cual organiza y difunde con familiares, amigos y conocidos. Si esta la califica como poco interesante o desagradable, entonces la desecha. Las relaciones interpersonales se encuentran mediadas por internet y un aparato (Ruano, Cogote y Torres, 2016).

Los jóvenes, principalmente, se encuentran en comunicación virtual constante, e ingresan a internet desde la casa, la escuela, el transporte colectivo o la plaza pública. La red internacional, así como los dispositivos, sobre todo el móvil, han permitido la interconexión cotidiana a través de mensajes personales o mediante el ingreso a una red o plataforma. La comunicación contemporánea no reconoce fronteras. Además, los jóvenes tienen a su alcance un cúmulo de información en contenidos culturales, sociales, políticos, mercantiles y financieros (García y Del Hoyo, 2013).

Esta realidad ha alterado las prácticas convencionales, porque ahora se realizan numerosas tareas desde cualquier espacio, la comunicación se estructura en redes de comunicación, en colectivos que conforman redes sociales para atender diversidad de asuntos. Los vínculos de efectúan por medio de dispositivos tecnológicos y de internet, lo que ha contribuido a difundir mensajes, realizar tareas escolares, saludar a los amigos y, algo importante, informarse y tomar partido en algún problema social, cultural, político o ciudadano. Las redes sociales son producto de la comunicación interpersonal que entablan sujetos durante un tiempo y que tienen un propósito compartido (Osorio, Molero, Pérez y Mercader, 2014).

Para García y Del Hoyo (2013), una red social es producto de internet y de la comunicación que entablan un número determinado de personas. Pueden ser abiertas a todo público o de uso restringido a un sector especial. Para Ruano, Cogote y Torres (2016), el dispositivo tecnológico más importante en la actualidad y que permite estar conectado permanentemente es el Smartphone. Varias condiciones han permitido esto: las numerosas campañas de mercadotecnia para ofrecer este artefacto, sus facilidades de pago, así como la oferta de tarjetas o planes mensuales de tiempo aire y libre acceso a internet en espacios públicos. La población más atraída por estos dispositivos son los jóvenes. Murden y Cardenaso (2018) asumen que los jóvenes cuyas edades oscilan entre los dieciséis y veintinueve años se conectan a internet vía el Smartphone, a diferencia de las personas de mayor edad, que prefieren la computadora personal o PC.

Estos cambios han modificado las formas de comunicación, pertenencia e identidad de los jóvenes. Las relaciones personales convencionales, por ejemplo, el trato personal directo no desaparecen, pero a la par han aparecido la comunicación y la convivencia virtual. Esta nueva forma de comunicación es inmediata; basta enviar un mensaje a uno o a varios amigos para encontrar eco en pocos minutos. Las diferentes 
redes sociales demuestran la diversidad de problemáticas que envuelven el mundo de vida de la juventud. Agrupan a numerosas personas de diferentes lugares, con el propósito de socializar un libro, una canción, una película, un acontecimiento. Permiten conformar comunidades con intereses específicos. Las redes sociales agrupan a participantes con un interés común y que habitan en distintas latitudes y comparten fotografías, videos, noticias, memes, publicidad, etcétera. Decir comunidad significa que son personas con intereses comunes, que los une una causa afín, espacio para el intercambio de numerosas situaciones que atañen de modo directo a sus miembros.

Las redes sociales se han convertido en un acontecimiento social porque en ellas están involucradas millones de personas (Ruano, Cogote y Torres, 2016; Osorio et al., 2014). Para Aguilar y Said (2010), las comunidades virtuales abren múltiples posibilidades a los miembros de una red, porque les permite tener información de diverso tipo y, algo importante, son un medio para viajar virtualmente. El mundo al alcance de todos. Las barreras geográficas se eliminan; es viable conocer una ciudad del extranjero a través del dispositivo electrónico y, además, mantener contacto con personas que están en otro país, que hablan otro idioma y que son portadores de una cultura diferente.

Para estos autores, "resulta interesante observar cómo la espacialidad de un sujeto determinado ya no se limita a un cierto territorio determinado como un espacio físico, sino que a través del ciberespacio es posible ejercer su subjetividad desde diferentes espacios" (Aguilar y Said, 2010, p. 194). Una peculiaridad más es que ahora los jóvenes pueden estar en comunicación con 50 personas al mismo tiempo e intercambiar información "de carácter político, social o cultural, con un simple 'click"' (García y Del Hoyo, 2013).

\section{Nuevas modalidades identitarias}

Las formas convencionales de comunicación basadas en el uso de papel, como oficios, cartas, periódicos, revistas, así como la charla entre amigos o colegas, la reunión personal para resolver algún asunto, conviven con internet, las tecnologías de la información y las redes sociales. Es usual que una persona participe en múltiples comunidades y en cada una de ellas interactúa de diferente manera. Esto ha traído un cambio en los códigos de comunicación. Uno de ellos consiste en el modelo de emisor-receptor, el cual se diluye en la comunicación virtual, porque los jóvenes en "su uso intenso encuentran prácticas comunicativas de carácter más pragmático, más horizontales y con rompimientos lineales del modelo de emisor-mensaje-receptor" (Bermúdez, 2017, p. 164).

Otro cambio que podemos destacar es la creación de códigos comunicacionales específicos en las comunidades virtuales, en "al menos, tres elementos centrales: énfasis en la imagen, el uso de un lenguaje en particular y lo que se podría denominar indicadores de popularidad" (Murden y Cadenasso, 2018, p. 18). En efecto, aquel lenguaje amplio, con explicaciones exhaustivas, el auxilio de fuentes especializadas, en el presente, con el uso de las redes sociales, ha cedido el paso al lenguaje visual: videos, fotografías, dibujos, animaciones, o bien, imágenes que manifiestan emociones, así como memes, además de un lenguaje breve, acotado a lo que se busca transmitir (Murden y Cadenasso, 2018). 
Por el impacto que han tenido las redes sociales, especialmente en la población joven, estas se han convertido en una modalidad de socialización debido al intercambio cotidiano de numerosas experiencias; por tanto, son el espacio privilegiado para la edificación de identidad o identidades juveniles (Bernal y Angulo, 2013; Fernández, 2012).

Algunos investigadores han encontrado que los jóvenes utilizan las redes sociales tanto para mantener lazos con sus amistades como para entablar nuevas relaciones. No importa el contacto físico, sino lo básico es mantener comunicación constante. Una investigación internacional realizada con estudiantes de bachillerato de España, Argentina, Brasil y México encontró que todos conocían y usaban Facebook, YouTube y WhatsApp. En cuanto a la particularidad de los bachilleres de acuerdo con el país de origen, se encontró:

... los jóvenes españoles que participaron en el estudio señalaron conocer diversas redes sociales que les posibilitan la participación social. Las más habituales son Instagram, Twitter y WhatsApp. En este caso, en contraste con los jóvenes brasileños y mexicanos, señalaron utilizar con menor frecuencia Facebook. Asimismo, otra diferencia estriba en que los jóvenes españoles señalan el uso de páginas Web, especialmente citan la página de 'change.org' como una referencia que usan para firmar peticiones sociales. También identifican otras páginas Web, referidas a entidades sin fines de lucro que permiten realizar donaciones (Márquez, Corrochano y González, 2020, p. 101).

Los vínculos establecidos en las redes pueden ser profundos, de ahí que se señala que las redes han participado en procesos de subjetivación en los jóvenes y, por eso, se habla de identidad digital (Murden y Cardenasso, 2018). Este planteamiento coincide con el de García y Del Hoyo (2011), quienes, con el apoyo de distintas fuentes documentales, proporcionan diversos indicios para comprender que el uso intensivo de las redes por parte de los jóvenes no es solo un pasatiempo, sino que en ellas se intercambian numerosas experiencias. Estos autores agregan que las modalidades de participación en línea son "(1) política o cívica, (2) cultural o de ocio, y (3) de amistad o de relaciones sociales" (García y Del Hoyo, 2013, p. 115). Estos vínculos virtuales han ofrecido a los jóvenes la información, el análisis y la discusión de numerosas temáticas.

En efecto, las redes sociales son los "espacios idóneos para la expresión juvenil tanto en lo político como en lo social” (Domínguez, López y Ortiz-Henderson, 2017, p. 91). Las redes se emplean como un medio de difusión de acontecimientos importantes y también como un medio de contrainformación. Si los medios difunden una noticia tendenciosa que busca afectar a una organización social, a una persona, a un grupo o a una comunidad, las respuestas de los internautas se harán virales y aclararán, precisarán, rechazarán, según el caso. Del mismo modo, las redes sociales son un medio para un activismo digital en temas políticos, civiles o comunitarios. Los jóvenes participan comunicando toda aquella situación injusta por parte de personas con poder político o económico, y las que se surgen entre pares, los problemas ambientales, el apoyo a los grupos sociales en desventaja, entre otros. 


\section{Participación política y comunitaria en redes sociales}

Las nuevas identidades juveniles se expresan también contra las expresiones de injusticia. En Colombia, diversas investigaciones han analizado el uso social de las tecnologías digitales, las cuales han hecho "visibles sus sentidos políticos y una construcción más ética, fortalecida plenamente por la solidaridad, la cooperación y, sobre todo, por la posibilidad de ser y crear cuando se tiene al alcance una mediación tecnológica" (Bermúdez, 2017, p. 162).

Delgado y Arias (2008) asumen que las acciones colectivas que la juventud despliega en las redes sociales responden a las expresiones de injusticia social. Este tejido virtual ha logrado tener un lugar dentro de los medios de información, el cual era controlado por noticieros de radio y televisión, así como por la prensa. Actualmente, los sucesos transmitidos en los canales convencionales coexisten con los difundidos en las redes sociales. Este activismo social en redes inicia con la información que posee una persona o un grupo, quienes darán un clic como señal de aceptación y algunos más lo difundirán entre todos sus contactos (García y Del Hoyo, 2013; Sádaba, 2012).

Para Sádaba (2012), las redes virtuales, junto con los dispositivos tecnológicos, se han convertido en un terreno fértil para el activismo político, social y cultural. Este autor ofrece como ejemplo el movimiento emprendido por el pueblo Mapuche, localizado en el sur de Argentina. García y Del Hoyo (2013), mencionan otros ejemplos:

Se extiende por el mundo una nueva forma de activismo social. En los últimos años, los ciudadanos están siendo testigos de acontecimientos tales como las revoluciones árabes, las filtraciones de secretos de las embajadas de Estados Unidos y los Gobiernos de todo el mundo a través de WikiLeaks, las acciones del colectivo de ciber atacantes Anonymous contra compañías como Visa o Amazon, los movimientos del 15 M en España, Occupy en Estados Unidos o Yo soy 132 en México, las protestas en Rusia, o campañas electorales muy basadas en redes sociales como la que en 2008 llevó a Obama a la Presidencia de Estados Unidos (p. 114).

Otro tipo de expresiones juveniles a través de las redes sociales ha sido la difusión de problemas comunitarios. La participación comunitaria consiste en que los integrantes de una red tienen como propósito intervenir para que se mejore el bienestar de sus integrantes, o el de otros grupos que viven situación adversa socialmente, como son las comunidades de migrantes, los sectores que trabajan en zonas lejanas a su domicilio, los grupos indígenas que viven situaciones de discriminación en las ciudades, o los sectores que pierden su vivienda en una catástrofe natural (Márquez, Corrochano y González, 2020).

Un ejemplo específico de este tipo de participación es el papel que cumplieron las redes sociales en los terremotos de Chile en 2010 y Japón en 2011, y podemos agregar el de México en 2017. En los tres casos, la juventud en las redes tuvo un papel fundamental para que los damnificados se comunicaran con sus familiares, con familiares de damnificados y también entre ellos para mostrar los lugares donde se demandaba apoyo físico. Otras expresiones han sido la difusión de problemas que atañen a grandes grupos humanos, como los daños a la salud provocados por los residuos que una empresa arroja a un río, el apoyo para salvar a una especie en peligro de extinción, la tala inmoderada de bosques, la solidaridad con grupos desplazados por la violencia en alguna región del país, la defensa de los derechos humanos de las 
minorías para combatir la xenofobia, el racismo y la violencia de género (Murden y Cadenasso, 2018).

Morales (2012), por su parte, apunta que los jóvenes, a través de las redes sociales, han participado en luchas feministas, lésbico-gay-transgénero, reconocimiento de la ciudadanía étnica, la defensa del medio ambiente y la lucha espacios juveniles para realizar conciertos. Esto ha sido posible gracias al uso de los dispositivos tecnológicos y las redes sociales, las cuales han llevado a la "expansión de contenidos de identidades juveniles" (Morales, 2012, p. 70). Cuando una demanda social logra trascender los límites de un grupo y se convierte en una macrorred donde circulan convocatorias y demandas, estamos ante un nuevo activismo político, comunitario y cívico (Sádaba, 2012; Domínguez y López, 2015 y 2017; Domínguez, López y OrtizHenderson, 2017; Murden y Cadenasso, 2018). La participación de los jóvenes, sobre todo los de educación superior, se presenta en frentes políticos, comunitarios y ciudadanos:

... los y las jóvenes empiezan a afiliarse a distintos colectivos que convocan un sinnúmero de intereses -ambientales, culturales, económicos, religiosos, de diversidad sexual y género, etc.-, así como también desde sus vivencias y particulares visiones del mundo, construidas a partir de su condición generacional, configuran redes de acción y movilizaciones en torno a su propio reconocimiento como actores sociales (Delgado y Arias, 2008, p. 273).

Los principios o valores de estas acciones juveniles son la responsabilidad, la cooperación y la solidaridad con los sectores que ameritan ayuda (Bermúdez, 2017).

\section{LOS UNIVERSITARIOS Y LA SOLIDARIDAD}

Para Gutiérrez y Arbesú (2009), la solidaridad es una respuesta a la interdependencia entre los seres humanos. La especialización provoca que todos dependan de todos, porque los lazos externos a la voluntad de las personas posibilitan la cohesión. Esta idea es cercana a la expresada por Durkheim (1973), quien consideró que la solidaridad orgánica es producto de la especialización de las tareas productivas y de los vínculos que establecen los miembros de la sociedad moderna. Entre mayor especialización, mayor división del trabajo, por tanto, mayor solidaridad orgánica (Durkheim, 1973).

Razeto (1999), en una posición cercana a esta, asume que es el mercado el que facilita que cada sujeto necesite de otros, porque, al ofrecer un producto, alguien lo comprará. Quienes no pueden vender sus mercancías es porque no satisfacen necesidades "reales". Estas personas quedan fuera del mercado y de la solidaridad que entablan vendedores y consumidores (Razeto, 1999). Desde esta posición, la solidaridad es producto de la división social del trabajo (Durkheim, 1973), del mercado y la economía (Razeto, 1999), o la interdependencia (Gutiérrez y Arbesú, 2009). Es una actividad que los sujetos realizan, pero no son conscientes del sentido de esta; lo hacen porque la rutina así lo indica. La anonimia es su característica, sin que comprendan la solidaridad que entre ellos entablan.

Otra definición de solidaridad es aquella que la considera un valor, porque se convierte en un modo de ser, un elemento constitutivo de la vida social y la moral inherente a las sociedades humanas (Gutiérrez, 2011). Es la “ayuda mutua para enfren- 
tar problemas compartidos, responde a la benevolencia o generosidad para con los pobres y necesitados de ayuda" (Razeto, 1999, p. 1). Esta postura es cercana a la de Amengual (1993), quien afirma que son los vínculos y la interrelación entre los sujetos su centro. En consecuencia, la solidaridad consiste en el apoyo moral de unos hacia otros, situación posible porque es una relación asimétrica entre aquel que tiene y puede aportar algo a quien lo necesita. Todos forman parte de una sociedad porque son solidarios, pero un sector lucha por el otro, por el que está debilitado:

... el significado básico de la solidaridad, que consiste en que cada uno es responsable de todos y todos lo son de cada uno; uno para todos y todos para uno, o dicho en términos metafóricos y muy reales al mismo tiempo, llevar cargas del otro, pagar su deuda, luchar sus causas haciéndolas causa propia. Así, la solidaridad expresa al mismo tiempo dos cosas: 1) la unión o vinculación entre las personas y 2) la responsabilidad recíproca individual y personalizada respecto de cada uno y de todos en conjunto (Amengual, 1993, p. 136).

La diferencia entre la solidaridad como vínculo económico y la solidaridad como valor radica en que la primera responde a la división del trabajo y la interdependencia económica que ello implica, por tanto, el individuo solo ejecuta una actividad sin tener claridad que con esto él se solidariza con sus semejantes, porque con su trabajo contribuye a la reproducción social. La segunda, por su parte, es producto de acciones de corte social, las cuales tienen una intención porque se dirigen hacia los otros (Weber, 2002); son resultado de la moralidad y buscan ayudar a quien requiere apoyo por su desventaja estructural (por sus condiciones de vida desiguales a la media social) o por una circunstancia extraordinaria, como son los efectos de la naturaleza. “La 'acción social', por tanto, es una acción en donde el sentido aludido por su sujeto o sujetos está referido a la conducta de otros, orientándose por ésta en su desarrollo" (Weber, 2002, p. 5).

Sin negar que la vida económica permita la reproducción social por los numerosos intercambios diarios, para los fines de esta investigación debemos aceptar la solidaridad como un valor, específicamente, para ofrecer ayuda a quien lo requiera. La solidaridad es un valor que los sujetos expresan en acciones sociales encauzadas hacia personas, grupos o comunidades. No es una actividad anónima: quien se solidariza con alguien sabe que es necesario hacerlo porque se encuentra en una situación frágil, ya sea por recursos monetarios, por una pena moral o por una situación ajena a él. Se inclina por quien está en una situación de debilidad y requiere ayuda; convierte la deuda del otro en propia. Puede tratarse de personas que forman parte del círculo vital de quien se solidariza, como familiares, amigos, colegas, o personas ajenas, desconocidas, pero que se decide apoyar.

La solidaridad está orientada hacia determinadas personas o grupos. Es una acción social con "sentido". La solidaridad como un valor permite comprender el papel que cumplieron los jóvenes universitarios que se involucraron en el rescate y apoyo de quienes fueron afectados durante el terremoto de septiembre de 2017.

\section{Metodología}

En nuestra investigación utilizamos un diseño cualitativo y exploratorio. El referente empírico estuvo compuesto por estudiantes universitarios que cursaban el último 
año de licenciatura en Diseño Industrial en la Universidad Autónoma Metropolitana, Unidad Xochimilco, ubicada en la Ciudad de México. La población participante se conformó de 41 jóvenes, de los cuales 20 eran mujeres y 21 hombres; en su mayoría, tenían entre diecinueve y veinte años de edad. Les explicamos cuál era el propósito del estudio y todos aceptaron participar de forma voluntaria.

En cuanto al instrumento de recolección de datos empíricos, con base en los objetivos que guiaron la investigación, diseñamos un cuestionario, en formato en línea, que incluyó preguntas abiertas. Optamos por esta herramienta porque provee diferentes ventajas, entre otras, abarca el mayor número de los participantes, dado que estos pudieron responder el cuestionario a la hora y el día que ellos eligieron. Las preguntas fueron: después del terremoto, ¿realizaste alguna forma de participación/acción organizada con alguien más (familia/amigos/compañeros de la escuela/otro)? y ¿qué te motivó a realizar dichas acciones? Al final, les pedimos que describieran de manera pormenorizada la forma en que participaron en el terremoto y que mencionaran la(s) razón (es) o motivos de esta participación y cómo se sintieron ante esta situación de emergencia. Los estudiantes tuvieron acceso al cuestionario en línea durante dos semanas, del 2 al 13 de octubre de 2017.

\section{Análisis}

Los datos se examinaron por medio de un análisis temático reflexivo de tipo inductivo (Braun y Clarke, 2013); la codificación y el desarrollo de los temas se orientó por el contenido de los datos. Consideramos de suma importancia tomar en cuenta la subjetividad de los investigadores. El análisis se llevó a cabo por medio de diversos momentos, todos relacionados entre sí: familiarización con los datos; codificación de estos; identificación de patrones; revisión y nombramiento de temas; y escritura final. Con el objeto de facilitar la organización de los temas y contrastarlos con los que crearon los investigadores, recurrimos al software NVivo (QSR version11 Pro). Después de todo este proceso, definimos cuatro temas: organización familiar; participación estudiantil en redes sociales; aplicación de los conocimientos adquiridos en la universidad; y empatía y solidaridad.

\section{RESULTADOS}

\section{Organización familiar}

Como mencionamos, los jóvenes tienen diferentes tipos de participación, a saber, social, política, ciudadana y comunitaria. En los testimonios expresados por los estudiantes que colaboraron en esta investigación advertimos que su involucramiento en el sismo fue una participación comunitaria. Esta modalidad consiste en la solidaridad hacia las personas que se encuentran en una situación adversa (Márquez, Corrochano y González, 2020). Los damnificados por el terremoto se encontraron en esta circunstancia, por tanto, en las redes se solicitó apoyo para el rescate de personas, sus pertenencias, sus mascotas, o bien, trasladar de un lugar a otro cierto tipo de víveres, agua, medicamentos o equipo de trabajo. En todas estas tareas, los universitarios tuvieron un papel importante. 
La participación comunitaria responde a principios éticos, porque para los estudiantes es un deber apoyar a la población en situación frágil. Los estudiantes de esta universidad vivieron las repercusiones del terremoto que azotó a México en 2017, porque esta institución se ubica en una de las demarcaciones afectadas. En la mayoría de los relatos se menciona que la forma de organización preponderante poco después del terremoto fue agruparse con algunos miembros de su familia: padres, hermanos, novias (os), con los que realizaron una serie de actividades para ayudar a las personas afectadas.

Los estudiantes se dirigieron tanto a edificios derrumbados como a centros de acopio. Las distancias no importaron, porque se visitó a damnificados en la Ciudad de México y en poblaciones del estado de Morelos. Un testimonio ilustra esta situación: "Con mi familia y algunos amigos juntamos víveres y medicamento para llevarlos a los multifamiliares de Tlalpan. Algunos de los víveres fueron llevados a Jojutla". Otros lugares visitados fueron centros de acopio, donde necesitaban "materiales de curación, suero, latas de comida, cobertores". Una actividad más consistió en abrir "las puertas para que todas las personas que pasaban por ahí pudieran entrar gratis al baño y hablar por teléfono". En otro caso, "mi hermano, su novia y yo, organizamos un espacio para poder darle asilo a todas las mascotas perdidas que andaban caminando en las calles cercanas de mi colonia".

Los familiares, como integrantes del mundo de vida de los jóvenes, cumplieron un papel relevante en la emergencia suscitada posterior al terremoto. Se organizaron para ofrecer soluciones, ya sea para llevar víveres a distintos puntos o adaptando la casa para solucionar problemas de quien lo necesitara.

\section{Participación estudiantil en redes sociales}

Los jóvenes y los estudiantes de educación superior están inmersos en el mundo digital. Los dispositivos tecnológicos y el internet les dan la posibilidad de informarse, viajar, difundir, criticar, apoyar, rechazar tanto noticias como acontecimientos, eventos políticos o culturales. En las redes dan a conocer situaciones favorables o injustas. Las redes son un medio de comunicación constante, no respetan horario, cualquier hora del día es buena para propagar información positiva o negativa. Los jóvenes participan en una o varias redes y también en uno o en varios grupos organizados en diversas temáticas. La ética a través de valores como la responsabilidad y la solidaridad estuvieron presentes en varios mensajes que circularon en red. Un evento extraordinario como el terremoto de 2017 movilizó a la población en general, y a los estudiantes universitarios en particular, para comprometerse y ejercer un papel destacado en las tareas de apoyo y rescate.

Conforme avanzamos en el trabajo de análisis, corroboramos que en cuanto se restableció la comunicación digital, estos jóvenes desplegaron su habilidad en el empleo de redes sociales como Facebook, Twitter, WhatsApp, YouTube, Messenger, entre otros, para comunicarse con amigos, compañeros e incluso con desconocidos, con el objeto de informarse e informar en qué zonas de la ciudad requerían ayuda. En las redes circularon fotos, direcciones de albergues donde solicitaban lo mismo rescatistas que herramientas o medicinas. El celular, como un aditamento 
privilegiado, les permitió conectarse con familiares, amigos, compañeros y profesores. El siguiente fragmento ilustra esto:

Junto con mis amigos subimos fotos, en las redes sociales, de las zonas de derrumbes y de los albergues en donde solicitaban cuestiones específicas, como por ejemplo en CU [Ciudad Universitaria], hubo un momento en que ya no requerían comida, sino que lo urgente era conseguir medicamentos de todo tipo.

Los universitarios utilizaron las redes sociales como el medio primordial de difusión de un acontecimiento social tan importante como fue el terremoto y sus consecuencias. Estas redes contribuyeron a que se organizaran en brigadas diversas. Los estudiantes, en sus relatos, explican cómo en todo momento, antes de subir a las redes la información requerida, verificaban su autenticidad. En la mayor parte de los relatos del trabajo de campo, los informantes aseveran que, a pesar de no conocer a las personas que integraban las brigadas, las redes sociales les ayudaron para incorporarse a diversos grupos con el afán de ir a remover escombros a las zonas de desastre:

Después de informarme por internet sobre las zonas de derrumbe más vulnerables, acudí por mi cuenta, específicamente, a la calle de Bolívar en la colonia Obrera en la Ciudad de México, para realizar voluntariado para remover escombros, retirar muros, cortar varillas, organizar brigadas, distribuir alimento y agua a voluntarios.

Un gran número de jóvenes narran que, por medio de WhatsApp, se enteraron de que sus profesores y compañeros organizaron brigadas a las que se unieron para ir a diversas zonas de derrumbe. De acuerdo con sus relatos, el cursar una licenciatura de Diseño Industrial, afín de alguna manera a la licenciatura en Arquitectura, les sirvió para comprender, junto con los profesores de Arquitectura, cómo se elaboraba un diagnóstico constructivo de las viviendas afectadas por el terremoto:

El primer día solo levanté escombros porque no llevaba botas ni casquillos. Al siguiente día conseguí que un profesor, quien ha sido mi amigo, que permitiera entrar por mis botas a mi locker. El profesor también me prestó guantes y demás equipo para poder ayudar más allá de solo levantar piedras, porque para ayudar en estas tareas se requería llevar equipo de protección.

\section{Aplicación de los conocimientos adquiridos en la universidad}

Uno de los objetivos generales del plan de estudios del licenciado en Diseño Industrial de la Universidad Autónoma Metropolitana, Unidad Xochimilco, es "formar profesionales que conozcan, manejen y apliquen los procesos teóricos, técnicos y formales del Diseño Industrial en la solución de problemas conceptuales de diseño y que sean capaces de producir artefactos objetos de claridad que satisfagan las necesidades de la sociedad" (Universidad Autónoma Metropolitana, 2011, p. 5). De lo anterior se desprende que su orientación es técnica, el núcleo es el saber hacer, diseñar herramientas novedosas que incidan en los procesos de producción y distribución de bienes. Se busca que se diseñen y produzcan artefactos con el propósito principal de satisfacer necesidades humanas de manera responsable. Algo que sorprendió encontrar en el material empírico fue que estos jóvenes lograron aplicar los conocimientos aprendidos en la licenciatura en la solución de percances que se presentaban en las zonas de desastre: 
Yo utilicé mi experiencia como diseñador industrial y me hice cargo de un almacén el que proporcionaba herramientas que yo conocía y que se necesitaban para remover escombros.

Mi trabajo en el multifamiliar fue aplicando conocimientos de diseñador industrial. Hice mesas en el área de carpintería, con polines enormes.

Me puse a cortar varillas con mayor precisión y rapidez, a diferencia de otras personas que no sabían cómo utilizar el esmeril.

Los anteriores testimonios demuestran que los conocimientos y las habilidades que los universitarios aprendieron en la licenciatura en Diseño Industrial sirvieron para solucionar problemas prácticos, como proporcionar la herramienta adecuada para cada cosa; diseñar objetos necesarios para solucionar problemas; cortar varilla de manera eficiente y emplear la herramienta precisa.

Otro tipo de conocimientos aprendidos en los espacios informales de la institución se relacionan con la aceptación o rechazo de las noticias que circulan en redes. Ante la acometida de cientos de mensajes, varios de ellos falsos, los estudiantes han aprendido que es necesario verificar su autenticidad. Para Márquez, Corrochano y González (2020), una competencia en los jóvenes es "la capacidad para indagar y comunicarse, que integra la capacidad de observación, sistematización de datos, y análisis sobre la validez, veracidad y pertinencia de la información" (p. 95). No es suficiente recibir noticias o mensajes, sino que es menester validar su autenticidad.

\section{Empatía y solidaridad}

La empatía se puede enfocar desde múltiples disciplinas; en este texto nos referimos a ella a través de la psicología, ya que las respuestas de los estudiantes se interpretan desde el ámbito de las emociones. De acuerdo con el Diccionario de Psicología (Galimerti, 2006), "la empatía es la capacidad de identificarse con otras personas hasta comprender sus pensamientos y sus estados de ánimo" (p. 383). Para Rogers (1989), es la posibilidad que tienen los seres humanos para comprender lo que está viviendo el otro. La gran mayoría de los relatos de estos jóvenes explican cómo el ponerse en el lugar de las personas damnificadas los motivó a realizar un sinnúmero de acciones con el afán de poder ayudar a los que se encontraban en desgracia:

... saber que mi familia pudo ser una de las afectadas, me motivó a poner mi grano de arena para que entre todos pudiéramos salir más rápido de esta desgracia.

Darme cuenta de la situación en la que se encontraban las personas afectadas por el desastre, tocó fibras sensibles que me hicieron querer ayudar.

Nunca vamos a dejar de sentir las ganas de ayudar y dar la mano a quien lo necesita, somos una sociedad muy "acomedida", diría mi bisabuela.

Olmedo y Montes (2009) señalan que "el concepto de empatía está relacionado con la comprensión del otro y de su mundo afectivo, a la que se llega como resultado de conectar con los sentimientos ajenos" (p. 4). 
En cuanto a la solidaridad, el análisis de las narraciones de estos jóvenes nos permitió identificar y nombrar los temas, a partir de los cuales consultamos diversas fuentes teóricas con las que los sustentamos. Esto nos ayudó a comprender que el sentimiento de empatía que experimentaron los universitarios los llevó como segundo momento a ser solidarios con las personas que estaban en desgracia. La solidaridad se expresa tanto con personas que conocemos como hacia personas desconocidas: "No conocía a nadie, pero a todos nos unía querer ayudar a los demás, sin saber a quién estábamos ayudando". Estas acciones tuvieron como fondo un sentido ético, una responsabilidad ciudadana: "Me decidí a ayudar porque tenía una obligación moral de apoyar a los ciudadanos que se encontraban en desgracia".

La solidaridad con los grupos en desventaja se convierte en una responsabilidad para apoyar a quien requiere auxilio. La solidaridad es hacer propia la deuda de otro (Amengual, 1993): “No podía hacer nada 'normal' sin dejar de pensar por un segundo en esas personas que no pudieron salir y que estaban enterradas bajo los escombros [...]. Preferí emplear mi tiempo haciendo algo que valiera la pena para mi existencia". Este sentimiento que motivó a los jóvenes a emprender numerosas acciones también les dio la oportunidad de experimentarla con los ciudadanos que ameritaban ayuda en las zonas de desastre:

Trabajábamos de madrugada, pero la gente nos tenía muy consentidos a todos nosotros con sus donaciones, había señoras que pasaban, varias veces, con sus botes con pozole o tamales y nos los regalaban.

Fue muy lindo sentir ese apapacho indiscriminado por parte de todas las personas que deseaban ayudar a los que estábamos trabajando en tareas de rescate.

También se ha mencionado en la parte teórica que las personas se solidarizan con algo o con alguien porque se convierte en un deber hacerlo, especialmente si se trata de un grupo o comunidad que se encuentra en una situación difícil. En los relatos de los jóvenes se constata este sentimiento, el cual se expresó al experimentar "enojo, frustración, decepción e impotencia".

\section{SOLIDARIDAD: ENOJO, FRUSTRACIÓN, DECEPCIÓN, IMPOTENCIA}

Es importante aclarar que, conforme fuimos analizando más finamente el tema de solidaridad, surgieron otros subtemas relacionados con este, como frustración y enojo: "La falta de organización en las zonas de desastre me motivó a ayudar porque me sentí frustrado y enojado de darme cuenta de que los damnificados por el terremoto estaban solos"; impotencia: "Lo que me llevó a ayudar fue un sentimiento de impotencia al intentar ponerme en los zapatos de los otros y de sus familias o seres queridos"; y tristeza y decepción: "Ayudé en todo lo que pude por la tristeza y decepción que me dio darme cuenta de la irresponsabilidad del gobierno y su incompetencia".

La solidaridad, vista como un valor, ayuda a comprender la particularidad social que caracterizó a estos jóvenes universitarios. Estos sujetos forman parte de un contexto histórico y tecnológico con características propias, que los llevó a que se involucraran en el rescate y apoyo de las personas afectadas durante el terremoto de septiembre de 2017. 


\section{CONCLUSIONES}

La participación de los jóvenes actuales en la vida política, comunitaria o ciudadana no es la misma que tuvieron las generaciones anteriores, cuyo centro eran la militancia y el activismo político directo. En la actualidad, la mayoría de los universitarios disfrutan horas manipulando una PC, una laptop, una tableta o un celular. Con estos artefactos y con internet, se conectan y rebasan fronteras, el mundo en un celular (Fernández, 2012). No hay límites para la información, la cual circula a una velocidad inmediata. En nuestro caso, los estudiantes, a través de las redes sociales, comunicaron los lugares donde requerían víveres, herramientas o ayuda física para rescatar personas o para trasladar materiales de uno a otro punto. Los universitarios se solidarizaron con aquellas personas damnificadas con este desastre natural.

Aranda (2017) considera que la diferencia entre los jóvenes que participaron en el rescate de la catástrofe de 1985 y los de 2017 fue que los primeros se informaron sobre los lugares que demandaron apoyo a través de mensajes en radio. Los segundos, por su parte, lo hicieron por las redes sociales, las cuales usaron, sin que una autoridad lo solicitara u organizara, para comunicarse, organizarse y acordar una estrategia de apoyo. La horizontalidad permitió la autoorganización, la formación de brigadas, ir a la calle en bicicleta, motocicleta o a pie.

Lo mensajes circulaban en los dispositivos y se indicaba el lugar donde requerían herramientas, agua, comida, fuerza de trabajo, etcétera. Los jóvenes, lo mismo trabajaron con los integrantes del grupo familiar, o con los miembros del grupo de pertenencia, o con la brigada formada por los compañeros, o por profesores y estudiantes, otras veces con personas desconocidas. Las redes sociales cumplieron un papel importante posterior al desastre. A través de ellas, los jóvenes universitarios ubicaron los lugares para apoyar a quien lo demandara.

Si la solidaridad como un valor consiste en apoyar a alguna persona, a un grupo o a una comunidad en desventaja, entonces los estudiantes que se involucraron en los días posteriores al terremoto de septiembre 2017 fueron solidarios. Nadie los envió, sino que ellos decidieron colaborar, hacer algo por aquellas personas damnificadas. En ese acontecimiento extraordinario se entendió la importancia que tuvieron "la telefonía celular, el GPS y las redes" (Amador, 2017). Los jóvenes universitarios demostraron que la apatía e indiferencia que se les adjudica no es tal, sino que los asuntos públicos los resuelven en las redes y, cuando es indispensable, participan físicamente y salen de su pequeño territorio.

Esta indagación proporcionó una enseñanza para quienes colaboramos en ella: el estudio de los sujetos de una sociedad específica, en este caso, de los jóvenes universitarios, se debe realizar considerando su particularidad histórica. A su vez, esto remite a introducirse en la vida cotidiana de estos, anotar lo que hacen, documentar los indicios (Ginzburg, 1983) que tejen en sus numerosas acciones diarias, y registrar e interpretar aquello que aparentemente no es relevante en la investigación social. 


\section{REFERENCIAS BIBLIOGRÁFICAS}

Aguilar Rodríguez, D. E. y Said Hung, E. (2010). Identidad y subjetividad en las redes sociales virtuales: caso de Facebook. Revista del Instituto de Estudios en Educación Universidad del Norte, núm. 12, pp. 190-207. Recuperado de http:// rcientificas.uninorte.edu.co/index.php/zona/article/viewFile/1145/725

Amador, J. (2017). Los millennials del 19-S podrían impulsar la transformación de México: investigadores. Proceso, 2 de octubre. Recuperado de https:// www.proceso.com.mx/505754/los-millennials-del-19s-podrian-impulsarla-transformacion-mexico

Amengual, G. (1993). La solidaridad como alternativa. Notas sobre el concepto de solidaridad. Dimensiones críticas de la filosofía política. Revista Internacional de Filosofía Política, núm. 1, pp. 135-151. Recuperado de http://e-spacio. uned.es/fez/eserv/bibliuned:filopoli-1993-1-EDC02288-AC9D-03F8-48A4C7CAB120E112/solidaridad_alternativa.pdf

Aranda, J. (2017). El sismo de los millennials. La jornada, 27 de septiembre. Recuperado de https://www.jornada.com.mx/2017/09/27/opinion/a04a1cul

Braun, V. y Clarke, V. (2013). Successful qualitative research: A practical guide for beginners. Londres: SAGE.

Bermúdez Grajales, M. M. (2017). Subjetividades juveniles, expresiones políticas y uso de tecnologías digitales. Praxis \& Saber, vol. 8, núm. 17, pp. 155179. Recuperado de https://revistas.uptc.edu.co/index.php/praxis_saber/ article/view/7205/5696

Bernal, C. y Angulo, F. (2013). Interacciones de los jóvenes andaluces en las redes sociales. Comunicar, Revista Científica de Educomunicación, núm. 40, vol. XX, pp. 25-30. http://dx.doi.org/10.3916/C40-2013-02-02

Castells, M. (2002). Internet y la sociedad red. Lección inaugural del programa de doctorado sobre la sociedad de la información y el conocimiento. Universitat Oberta Catalunya. Recuperado de http://fcaenlinea.unam.mx/anexos/1141/1141_u5_act1.pdf

Delgado Salazar, R. y Arias Herrera, J. C. (2008). La acción colectiva de los jóvenes y la construcción de ciudadanía. Revista Argentina de Sociología, vol. 6, núm. 11, pp. 272-296.

Domínguez, F., López, R. y Ortiz-Henderson, G. (2017). Redes sociales digitales y participación política de jóvenes universitarios de México y de Chile: una revisión de estudios. Revista Latinoamericana de Ciencias de la Comunicación, vol. 14, núm. 26, pp. 86-95. Recuperado de https://www.alaic.org/revista/ index.php/alaic/article/view/911/476

Domínguez, F. y López, R. (2017). Redes sociales digitales: espacios de participación política, ciudadana y de derechos humanos para los jóvenes universitarios mexicanos. En R. Torres, G. Urzúa y J. C. Sánchez (eds.). Juventud y espacios de participación en Chile y América Latina (pp. 93-110). Santiago: Universidad Central/RIL Editores.

Domínguez, F. y López, R. (2015). Uso de las redes sociales digitales entre los jóvenes universitarios en México. Hacia la construcción de un estado de conocimiento (2004-2014). Revista de Comunicación, núm. 14, pp. 48-69.

Durkheim, E. (1973). De la división del trabajo social. Argentina: Schapire Editor.

Fernández, C. (2012). Ciudadanía juvenil y nuevas formas de participación a través de la conectividad. Culturales, vol. 8, núm. 15, pp. 114-134. Recuperado de http://www.scielo.org.mx/pdf/cultural/v8n15/v8n15a5.pdf 
Galimerti, U. (2006). Diccionario de Psicología (2a. ed). México: Siglo XXI Editores.

García Galera, M. C. y Del Hoyo, M. (2013). Redes sociales, un medio para la movilización juvenil. Zer, vol. 18, núm. 34, pp. 111-125. Recuperado de https:// ojs.ehu.eus/index.php/Zer/article/view/10649/9887

Ginzburg, C. (1983). Señales. Raíces de un paradigma indiciario. En A. Gargani (comp.). Crisis de la razón. Nuevos modelos en la relación entre saber y actividades humanas (pp. 55-99). México: Siglo XXI.

Gutiérrez, S. (2011). Representaciones sociales y construcción de ciudadanía en jóvenes universitarios. Sinéctica, revista electrónica de educación, núm. 36, pp. 1-18. Recuperado de https://sinectica.iteso.mx/index.php/SINECTICA/ article/view/120/113

Gutiérrez, S. y Arbesú, I. (2009). Los estudiantes de la Universidad Autónoma Metropolitana, Xochimilco y sus percepciones sobre ciudadanía. En J. Piña y O. Mireles (coords.). Ciudadanía y estudiantes universitarios (pp. 213-273). México: Gernika.

Lévy, P. (2007). Cibercultura. La cultura de la sociedad digital. Informe al Consejo de Europa. Barcelona-México: Anthropos-Universidad Autónoma Metropolitana.

Márquez, A., Corrochano, M. C. y González, M. R. (2020). Redes sociales (RR. SS.), tres miradas a la participación de los jóvenes a través de las RR.SS. En J. Igelmo Zaldívar y M. R. González (2020). Participación cívica en espacios socioeducativos. Panorama iberoamericano en un mundo tecnológico (pp. 91-122). Salamanca, España: Editorial Fahren House, colección Grupo Cultura Cívica y Políticas Educativas, núm. 2. Recuperado de https://www.fahrenhouse.com/ omp/index.php/fh/catalog/book/42

Medina, M. (2007). Prólogo al libro Pierre de Lévy. Cibercultura. La cultura de la sociedad digital (pp. VII-XXIV). Informe al Consejo de Europa. México: UAMIztapalapa-Anthropos.

Morales, M. (2012). Juventud y acción colectiva en México. Revista del Centro de Investigación, vol. 10, núm. 37, pp. 67-82. Recuperado de http://revistasinvestigacion.lasalle.mx/index.php/recein/article/view/105

Moreno, A. (2017). Radiografía de los voluntarios. El Financiero, 6 de octubre.

Murden, A. y Cadenasso, J. (2018). Ser joven en la era digital. Una aproximación a los procesos de construcción de subjetividad. CEPAL. Recuperado de https:// dds.cepal.org/redesoc/publicacion?id=4739

Olmedo, P. y Montes, B. (2009). Evolución conceptual de la empatía. Iniciación a la investigación. Recuperado de https://revistaselectronicas.ujaen.es/index. php/ininv/article/view/307

Osorio Cámara, M. J., Molero Jurado, M. M., Pérez Fuentes, M. C. y Mercader Rubio, I. (2014). Redes sociales en internet y sus consecuencias de uso en estudiantes universitarios. Revista de Psicología, vol. 3, núm. 1, pp. 585-592. http://dx.doi.org/10.17060/ijodaep.2014.n1.v3.539

Razeto, L. (1999). La economía de la solidaridad: concepto, realidad y proyecto. Persona y Sociedad, vol. XIII, núm. 2, pp. 1-14. Recuperado de http://base. socioeco.org/docs/razeto_la_economia_de_solidaridad_06.pdf

Rogers, C. (1989). El proceso de convertirse en persona. Barcelona: Paidós.

Ruano, L., Congote, E. y Torres, A. (2016). Comunicación e interacción por el uso de dispositivos tecnológicos y redes sociales virtuales en estudiantes universitarios. 
RISTI. Revista Ibérica de Sistemas e Tecnologías de Información, núm. 19, pp. 1531. Recuperado de http://www.risti.xyz/issues/risti19.pdf

Sádaba, I. (2012). Acción colectiva y movimientos sociales en las redes digitales. Aspectos históricos y metodológicos. ARBOR. Ciencia, Pensamiento y Cultura, vol. 188, núm. 756, pp. 781-794. https://doi.org/10.3989/ arbor.2012.756n4011

Senado de la República (2017). Coordinación de comunicación social, núm. 389. Recuperado de http://comunicacion.senado.gob.mx/index.php/informacion/boletines/39320-plantean-integrar-a-las-zonas-en-desastrey-emergencia-en-las-zonas-de-atencion-prioritaria.html

Servicio Sismológico Nacional (2018). Catálogo de sismos. Recuperado de http://www2.ssn.unam.mx:8080/catalogo/

Universidad Autónoma Metropolitana (2011). Resultados de la encuesta aplicada a egresados de la licenciatura en Diseño Industrial. División de Ciencias y Artes para el Diseño, Unidad Xochimilco. Recuperado de http://www. uam.mx/egresados/estudios/acreditacionlic/Unidad_Xochimilco/5_2011/ Plan_87_Licenciatura_en_Diseno_Industrial_XOC_CAD_2011.pdf.

Weber, M. (2002). Economía y sociedad. Madrid: FCE. 